\title{
A centrifugally controlled circuit in the avian retina and its possible role in visual attention switching
}

\author{
PETER G.H. CLARKE, ${ }^{1}$ MARCEL GYGER, ${ }^{2}$ AND STEFAN CATSICAS ${ }^{1}$ \\ 'Institute of Cell Biology and Morphology, University of Lausanne, Switzerland \\ ${ }^{2}$ Nestec Ltd., Nestlé Research Centre, Lausanne, Switzerland \\ (Received March 1, 1996; ACCEPTEd April 29, 1996)
}

\begin{abstract}
The isthmo-optic nucleus (ION) is the main source of efferents to the retina in birds. Isthmo-optic neurons project in topographical order on amacrine cells in the ventral parts of the retina, and a subclass of these known as proprioretinal neurons project onto the dorsal retina. We propose that, through the intermediary of the amacrine target cells, activity in the isthmo-optic pathway excites ganglion cells locally in the ventral retina but inhibits those in dorsal regions. This circuit would thereby mediate centrifugally controlled switches in attention between the dorsal retina, involved in feeding, and the more ventral parts, involved in scanning for predators. This hypothesis accounts for a wide range of disparate data from behavior, comparative anatomy, endocrinology, hodology, and neurophysiology.
\end{abstract}

Keywords: Attention, Birds, Centrifugal fibers, Isthmo-optic nucleus, Vision

\section{Introduction}

Centrifugal projections to the retina have been described in all classes of vertebrate (Repérant et al., 1989), but the avian isthmo-optic projection is the largest and best studied. It arises from the contralateral isthmo-optic nucleus (ION), lying at the meso-rhombencephalic border, and from a group of neurons called the "ectopic isthmo-optic cells," scattered around the ION (Uchiyama, 1989; Clarke, 1992). Both the ION and the ectopic cells receive strong input from the ipsilateral optic tectum, and the ION is also known to be influenced by a descending input from the visual telencephalon (Uchiyama et al., 1987). The axons from the ION proper terminate in spatially restricted endings (including, in pigeons, "convergent" and "divergent" subtypes - Maturana \& Frenk, 1965), giving one pericellular nest containing many synapses on a single amacrine cell as well as minor branches to other nearby amacrines (Ramon y Cajal, 1893) and perhaps to displaced ganglion cells (Maturana \& Frenk, 1965). In contrast, the axons of the ectopic neurons give widespread arborizations in the inner plexiform layer (Fritzsch et al., 1990).

The role of the ION in behavior is unclear. Lesions of it leave visual acuity and pattern recognition largely unaffected (for review, see Hahmann \& Güntürkün, 1992). There is evidence that it may be involved in visual attention, as is discussed below.

We here propose a hypothesis according to which the ION is involved in the switching of attention between the upper parts

Reprint requests to: Peter G.H. Clarke, Institute of Anatomy, University of Lausanne, Rue du Bugnon 9, 1005 Lausanne, Switzerland. of the visual field, involved in pecking food, and the lower parts, involved in the detection of predators. Our hypothesis makes sense of data from behavior, comparative anatomy, endocrinology, hodology, and neurophysiology.

\section{The hypothesis}

\section{The need for attentional switching between retinal regions}

When a human or a monkey views an object, there is a division of labor between the low-acuity peripheral retina and the high-acuity fovea. A movement or flash in the periphery elicits fixation, but detailed analysis is done by the fovea and parafovea. In such a situation, extrafoveal attention is a transient event that precedes an eye movement to the region of interest.

In birds, the situation is more complex. Quite apart from the problem that we shall ignore of switching attention between the two eyes, there are new problems of directing attention to different regions of a single retina. In birds, almost the entire retina is endowed with high acuity, and detailed analysis can be performed throughout the visual field. There are, however, specializations within avian retinas, and usually there are two regions with somewhat higher acuity than the remainder of the retina: one in or near the binocular part of the temporal or supero-temporal retina and associated with pecking, the other more centrally placed and associated with lateral viewing. In most birds of prey, each of these specialized regions contains a fovea (Rochon-Duvigneaud, 1943). In pigeons, there is only one true fovea (i.e. foveal pit) for each eye, lying centrally, but there is a second area in the dorso-temporal retina, known as 
the "red area," whose acuity and density of ganglion cells and other cell types is almost equal to that of the fovea (Galifret, 1968; Binggeli \& Paule, 1969). The red area is used in pecking. In chickens, the situation is similar except that even in the central retina the region of higher acuity does not contain a foveal pit (Ehrlich, 1981).

Consider now the case of a chicken that is engrossed in pecking grains, when a hawk appears in its upper visual field (ventral retina). How will attention be switched from the dorsally placed red area to the urgently important image on the ventral retina? Clearly this will be important, and may be different from the kind of attention switching that occurs in the single fovea retinas of species such as our own.

\section{Connectivity between remote retinal regions as a basis for attentional switching}

According to our hypothesis, the switching of attention between dorsal and ventral retina will involve a reduction of activity throughout much of the dorsal retina owing to activation of cells in the ventral retina of the same eye (or perhaps of the other eye also, but we shall concentrate on homolateral effects), and will be mediated by the centrifugal projection. We propose that this is achieved mainly through activation by the ION cells of a class of centrifugally controlled retinal neurons known as the "proprioretinal neurons."

These were first described by Catsicas et al. (1987a) in chicks and chick embryos. They consist of a population of amacrine cells with very long tangential axons in the outer part of the inner plexiform layer, occurring throughout the ventral half of the retina, and projecting in topographic order onto the dorsal half as well as sending other long connections within the ventral retina (Fig. 1). These neurons are of two kinds, of which "type 1I", pear-shaped with a single stubby process running to the inner plexiform layer where it branches, resemble Cajal's "association amacrine cells," which he designated thus because he had observed them to have relatively long tangential axons (Ramon y Cajal, 1893). Ehrlich et al. (1987) described, in chicks, a population of substance P-like immunoreactive amacrines, each with a long thin process directed towards the dorsotemporal pole of the retina. Conceivably these may be proprioretinal type II cells. Since Cajal and others had already reported that the main recipient cells of the isthmo-optic axons were association amacrines, and since the distribution of the isthmo-optic terminals resembles that of the proprioretinal cells, being predominantly ventral in chicks (Catsicas et al., 1987b; Fritzsch et al., 1990), Catsicas et al. (1987a) proposed that the proprioretinal cells with association amacrine morphology were under centrifugal control. Even the type I proprioretinal cells may receive isthmooptic input because they resemble "flat amacrines," which sometimes receive minor branches of isthmo-optic fibers even though they do not receive pericellular nests (Maturana \& Frenk, 1965). It is therefore possible that both classes of proprioretinal cell may receive centrifugal innervation, although the evidence is strongest for the input onto association amacrines.

Many of the above findings have been confirmed in the quail by Uchiyama et al. (1995). They have shown that in quails, as in chickens, the isthmo-optic projection is exclusively to the ventral retina, and they have identified the main target cells by labelling the isthmo-optic fibers anterogradely, and then injecting Lucifer Yellow into the target. This revealed that, like the propri-
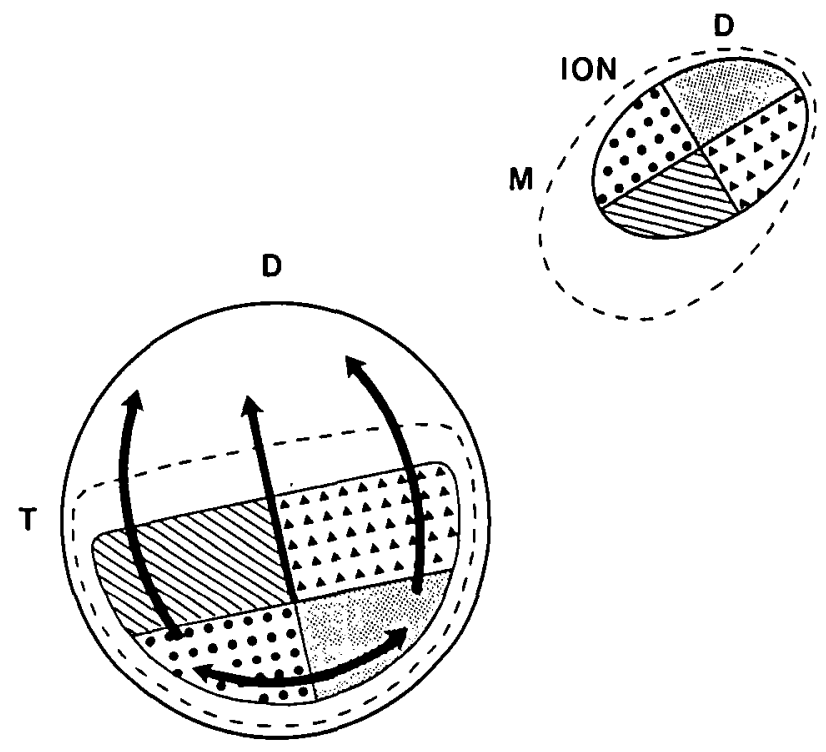

Fig. 1. Summary of the proprioretinal connections, as shown by thick arrows on a diagram of the right retina, and of the topography of the isthmo-optic projection. The left ION is shown to project in topographic order on the lower half of the right retina, although not to its most extreme periphery. The region containing the ectopic ION neurons is marked by discontinuous lines, as is their retinal projection zone, which includes that of the ION but extends more widely. D: dorsal; T: temporal; and $\mathrm{M}$ : medial.

oretinal cells of Catsicas et al. (1987a), these cells were association amacrines with long axons running tangentially at the junction of the inner nuclear and plexiform layers.

It has been suggested that the isthmo-optic projection itself might provide its target neurons with information about remote retinal regions (Holden, 1990). This was argued primarily on the grounds that in the pigeon the receptive fields of ION neurons were found by Holden and Powell (1972) to be located mainly in the dorsal retina (lower visual field), whereas the terminals of the ION are most abundant (in pigeons) in a band near the horizontal meridian of the retina (Hayes \& Holden, 1983). However, the receptive-field data have never been checked (in pigeons) by another laboratory, and other reports on the location of isthmo-optic terminals are variable and only partly agree with those of Hayes and Holden (Maturana \& Frenk, 1965; Crossland \& Hughes, 1978; Woodson et al., 1995). In view of these discrepancies, and bearing in mind that the only direct evidence concerning isthmo-optic topography in the pigeon is compatible with the maintenance of topographical register (McGill et al., 1966), we think the evidence for a major mismatch between the distributions of receptive-field positions in the ION and isthmo-optic terminals in the retina is indecisive, even in the pigeon.

In the chick, there is solid evidence that the isthmo-optic projection does at least approximately respect retinal topography (i.e. that the receptive fields of isthmo-optic neurons are located near the retinal coordinates of their axon terminals). In this species, both the isthmo-optic terminals and the ION receptive fields are located mainly in the ventral retina (Miles, $1972 c$; Catsicas et al., 1987b; Fritzsch et al., 1990). Moreover, retrograde labelling from small placements of diI in the chick retina (Catsicas 
et al., 1987b) give a well-organized topography in the ION (Fig. 2) matching that of the receptive fields recorded by Miles (1972c): temporal retina represented medially in the ION and ventral retina dorsally.

\section{A proposed circuit for attentional switching}

In the light of the above discussion, we propose the following detailed circuit as a basis for attentional switching in chickens and quails (Fig. 3). (The circuit may be somewhat different in pigeons owing to their different retinal distribution of isthmooptic fibers.) Retinal ganglion cells project [directly and/or indirectly (Uchiyama \& Watanabe, 1985; Woodson et al., 1991)] onto the neurons of origin of the tecto-ION projection, which in turn project onto the isthmo-optic neurons. At each of these stages, topography is respected approximately and the predominant influence is excitatory (Clarke \& Whitteridge, 1976; Uchiyama, 1989). The ION neurons innervate amacrine cells in the ventral retina, their most powerful input being via pericellular nests onto association amacrines that we identify as type Il proprioretinal cells (Catsicas et al., 1987a). These project to ordinary amacrines in the dorsal retina that inhibit ganglion cells throughout the dorsal region involved in feeding. In addition, the ION neurons send minor axon branches onto other amacrines that include the "flat" and "small parasol" types (Maturana \& Frenk, 1965). Although the "flat amacrines" might be proprioretinal, for simplicity we merely show branches onto ordinary amacrines, by which we mean any amacrine that is not an association amacrine.

In the absence of definitive evidence, we assume that the ION neurons are excitatory, a view that is supported by evidence that at least some of them contain choline acetyltransferase (Bagnoli et al., 1992) and that their target cells receiving pericellular nests express excitatory nicotinic receptors (Nickla et al., 1994). Moreover, the only GABAergic neurons in the ION are a tiny population of interneurons (Miceli et al., 1995). We assume the association amacrines receiving pericellular nests to be excitatory, since they contain glutamate (Uchiyama et al., 1995). They appear not to receive any major input from within the retina (Uchiyama \& Ito, 1993; Uchiyama et al., 1995).

The remaining details of the centrifugally controlled retinal circuitry are unknown, but our proposal in Fig. 3 is designed to show how a single ION neuron and a single association amacrine may mediate local enhancement of the responses of many ganglion cells in the ventral retina, and long-range inhibition of many ganglion cells in the dorsal retina. The local (or, at least, ventral-to-ventral) enhancement is known to occur, and may involve the inhibition of amacrine cells that inhibit ganglion cells (Uchiyama, 1989), although excitatory routes cannot be ruled out (Uchiyama \& Barlow, 1994). There are 200 times more ganglion cells than isthmo-optic neurons, but the centrifugal projection is reported to influence most of the ganglion cells (Miles, 1972a; Pearlman \& Hughes, 1976). Whether the influences on the dorsal retina are in fact inhibitory, as we propose, is unknown.
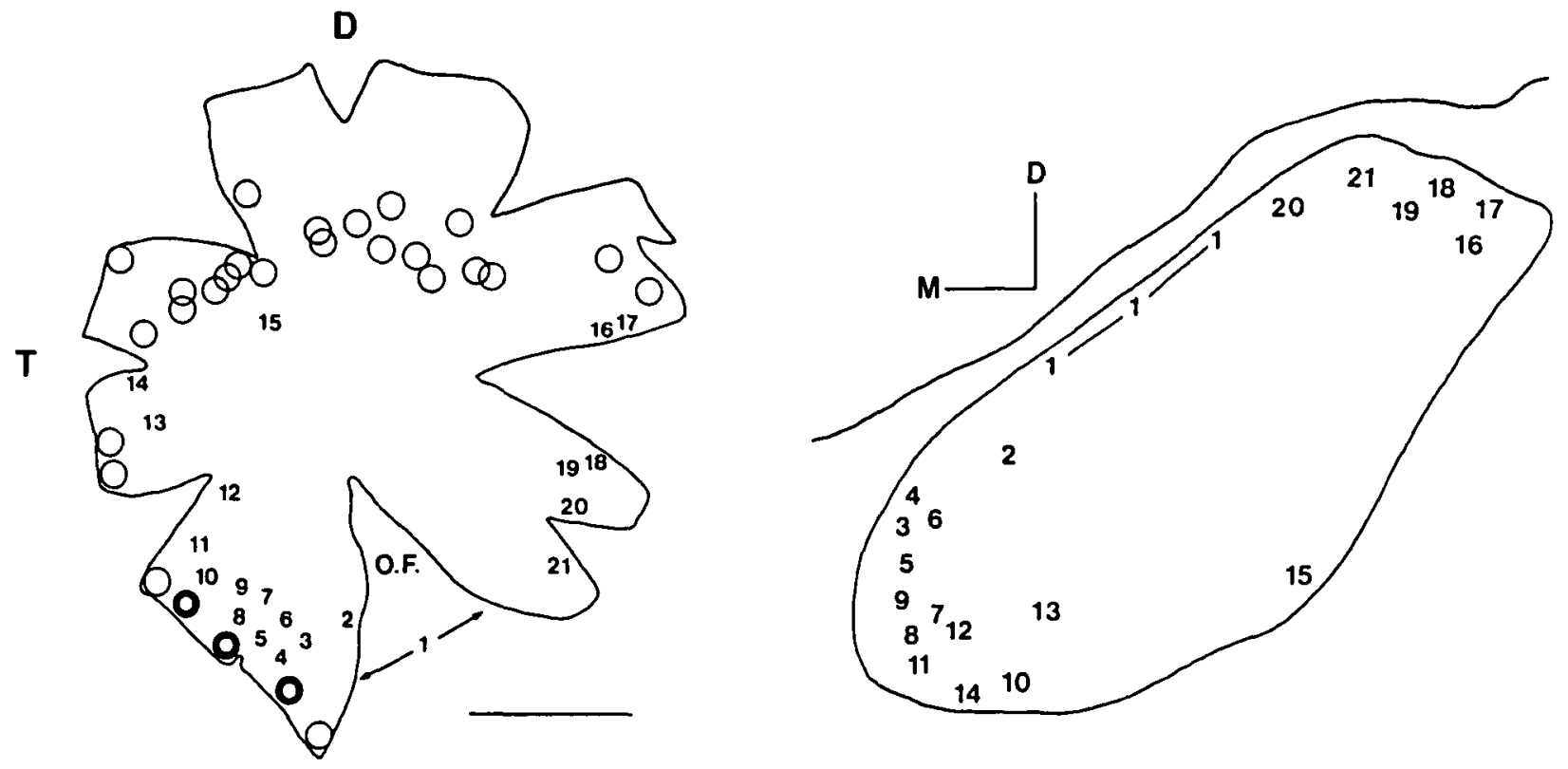

Fig. 2. Data showing the topography of the isthmo-optic projection in chicks, as indicated by 49 retrograde tracing experiments involving restricted placement of the carbocyanine dye "dil" in different parts of the right retina in chicks and chick embryos (Catsicas et al., 1987b). Left: The positions of the 49 dye insertion sites are summarized on a single retinal flatmount from a 3-day-old chick. From the 21 numbered sites, neurons were labelled in the ION (as well as ectopic cells in all except site 15). From the unnumbered sites, no neurons were labelled in the ION, but only "ectopic cells." These sites are shown by thick circles (many ectopic cells labelled) or thin circles (few ectopic cells). O.F.: optic fissure. D,T: denote dorsal temporal. Scale bar $=5 \mathrm{~mm}$. Right: Summary of labelling in the contralateral (left) ION from the 21 numbered retinal sites. In each case, the center of the most densely labelled region has been transposed onto a tracing of a typical coronal section through the middle of the ION and marked with the number of the retinal dye placement. The repeated is indicate a narrow labelled band along the dorsal edge of the ION. 


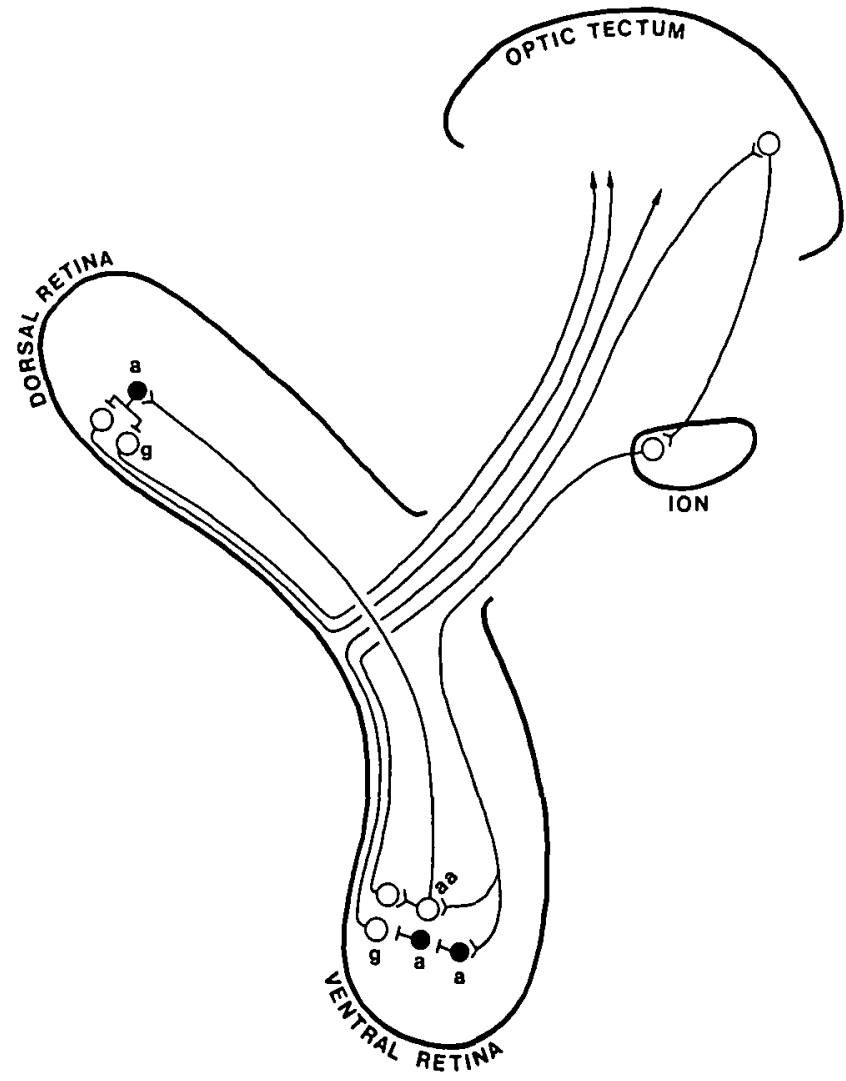

Fig. 3. Our proposed circuit for visual attention switching in the chicken and the quail. Retinal ganglion cells (g) activate tectal neurons directly or indirectly, and these in turn activate ION neurons, which give pericellular nests onto association amacrines (aa) and also innervate ordinary amacrines (a). Topographical register is respected thus far. The amacrines that are activated by the isthmo-optic axons cause excitation and/or disinhibition of most local ganglion cells, but the association amacrines are postulated to cause inhibition of remote ganglion cells in the dorsal retina, presumably through the intermediary of ordinary amacrines, each of which inhibits many ganglion cells (a). This diagram omits several details, such as inhibitory interneurons in the optic tectum and isthmo-optic nucleus. Open circles-excitatory neurons; filled circles-inhibitory neurons.

A strength of our hypothesis is that it can account for a wide variety of data.

\section{Data accounted for by the hypothesis}

\section{Behavior}

The observations of Rogers and Miles (1972) on the behavior of chicks with and without isthmo-optic lesions are particularly relevant. One experiment examined whether the lesions would affect the ability of the chicks to respond to a novel object (a red bead) moving into the visual field from behind while they were busy pecking grains. This was a direct evaluation of attention switching from the red field to other parts of the retina during feeding, and therefore serves as a direct test of our hypothesis. As we would predict, a major deterioration was found in this task.
At first sight our hypothesis might seem to be contradicted by the fact that ION lesions impair grain-grit discrimination as revealed in pecking tasks in both chicks (Rogers \& Miles, 1972) and pigeons (Hahmann \& Güntürkün, 1992), because activation of the ventrally placed proprioretinal cells (in chicks) should, according to our hypothesis, inhibit the dorsal retina (especially the red area). Destruction of the ION might therefore be expected to free the dorsal retina of this inhibition, leading to improved, rather than impaired, grain-grit discrimination. However, for technical reasons, the ION lesions were always made several days before the behavioral testing. After such a delay, deafferented cells can become hyperactive. If this occurred in the targets of the ION, it would explain the impaired discrimination. Moreover, the fact that grain-grit discrimination was affected in the lesioned chicks supports our view that the ION is involved in the influence of ventral retina on dorsal, since the ION does not in this species project directly to the dorsal part of the retina involved in the discrimination.

\section{Endocrinology}

The link with endocrinology stems from studies of alarm calling in response to predators. In several species of bird (and mammal), there is sexual dimorphism in calling behavior. For example, when male and female chickens are feeding together, cockerels produce many more alarm calls than hens in response to the appearance of an aerial predator (Gyger et al., 1985). In this case, the male acts as a sentinel, allowing the hen to spend maximal time obtaining food to be transformed into eggs. This difference is causally related to the higher levels of testosterone in cockerels, as has been shown by experimental variation of the testosterone level (Gyger et al., 1988). Since there is no effect of testosterone on another kind of call, food calling, this seems not to be a general effect on vocalization (Gyger et al., 1988). It therefore seems possible that the increased vocalization may be due to increased visual detection of the predators, and indeed it is known that the focus of attention on a part of the visual field is influenced by testosterone (Rogers \& Andrew, 1989). The question therefore arises whether testosteroneaccumulating cells are present in the visual system.

Labelling with tritiated testosterone gave a striking answer. The only truly visual structure in which such cells are detectable by autoradiography is the ION. This was shown by Meyer et al. (1976) in 6-day-old male chicks and confirmed by Barfield et al. (1978) in 8-week-old hens and castrated cockerels, although the latter authors were cautious about their identification of the ION because their histological procedures were inadequate to reveal its definitive structure.

\section{Comparative anatomy}

Comparative anatomy supports our hypothesis, because groundfeeding species of bird have the largest and best developed IONs (Repérant et al., 1989), and these are the species that have most need to switch attention between food and predators. Birds that feed on the wing, notably swifts and swallows, have few ION neurons (Feyerabend et al., 1994), and appear to have less to fear from predators while feeding (Schmid, 1995). Likewise the ION is small and poorly differentiated in birds of prey (Shortess \& Klose, 1977; Weidner et al., 1987). 


\section{Electrophysiology}

Our theory predicts that ION activity will tend to enhance retinal responsiveness in the topographically corresponding part of the retina, but will reduce responsiveness elsewhere, especially in the red area.

The first part of this electrophysiological prediction is abundantly confirmed by all relevant studies; ganglion cell responses being potentiated by stimulation of the ION. Several such reports do not specify the region of visual field concerned (Galifret et al., 1971; Miles, 1972a), but in one study in quails (Uchiyama \& Barlow, 1994) the receptive fields were deliberately confined to the upper visual field so as to involve the ventral retina where centrifugal terminals are most numerous. Furthermore, cooling the ION reduces the responsiveness of ganglion cells in unspecified parts of the retina (Pearlman \& Hughes, 1976), or prevents in some cells an enhancement due to the recent passage of a dark edge across the receptive field (Miles, 1972b).

The second part of the electrophysiological prediction has not, to the best of our knowledge, been adequately tested. The most long-range interactions reported in the avian retina extended for about $20 \mathrm{deg}$ (Brooks \& Holden, 1974; Holden, $1977 a, b)$, but those at longer range may be subtle and hard to demonstrate. In cats, such influences are particularly sensitive to anesthesia (Mcllwain, 1964).

\section{Critical tests of the hypothesis}

In addition to its ability to explain existing data, our hypothesis makes numerous new predictions, of which the most readily testable are the following.

Lesions of the ION should affect the behavior of chickens or quails in response to predators, including the number of alarm calls.

Modification of testosterone levels should affect neuronal activity in the ION, as well as visual behavior known to be affected by ION lesions. Previous publications have generally omitted such basic information as the sex of the birds studied. This should now be specified.

Centrifugal and long-range intraretinal influences on retinal ganglion cells need to be studied electrophysiologically. Stimulation of the ION or the isthmo-optic axons should enhance the responses of ganglion cells only in central or ventral retina, but should weaken them in the dorsal retina (in chickens or quails). Likewise, the interactions between two visual stimuli, in widely separated parts of the field, should be studied. An upper field (ventral retina) stimulus should inhibit the response to a lower field one, but not vice versa. Sectioning the isthmooptic tract should eliminate, or at least reduce, the upper-tolower field inhibition.

\section{Acknowledgments}

We thank Mrs. C. Vaclavik for typing the manuscript, and Dr. S. Clarke and Dr. M.-P. Primi for criticisms. Some of our own research on the isthmo-optic nucleus was supported by Grants 31-30883.91 and 31-40709.94 from the Swiss National Foundation for Scientific Research.

\section{References}

Bagnoli, P., Fontanesi, G., Alesci, R. \& Erichsen, J.T. (1992). Distribution of neuropeptide $Y$, substance $P$, and choline acetyltrans- ferase in the developing visual system of the pigeon and effects of unilateral retina removal. Journal of Comparative Neurology 318, 392-414.

Barfield, R.J., Ronay, G. \& Pfaff, D.W. (1978). Autoradiographic localization of androgen-concentrating cells in the brain of the male domestic fowl. Neuroendocrinology 26, 297-311.

Binggeli, R.L. \& PaUle, W.J. (1969). The pigeon retina: Quantitative aspects of the optic nerve and ganglion cell layer. Journal of Comparative Neurology 137, 1-18.

Brooks, B. \& Holden, A.L. (1974). Centre and surround influences on the proximal negative response of the pigeon retina. Journal of Physiology (London) 239, 15-29.

Catsicas, S., Catsicas, M. \& Clarke, P.G.H. (1987a). Long-distance intraretinal connections in birds. Nature 326, 186-187.

Catsicas, S., Thanos, S. \& Clarke, P.G.H. (1987b). Major role for neuronal death during brain development: Refinement of topographical connections. Proceedings of the National Academy of Sciences of the U.S.A. 84, 8165-8168.

Cl.ARKE, P.G.H. \& WhitTERIDGE, D. (1976). The projection of the retina, including the 'red area' on to the optic tectum of the pigeon. Quarterly Journal of Experimental Physiology 61, 351-358.

ClARKE, P.G.H. (1992). Neuron death in the developing avian isthmooptic nucleus, and its relation to the establishment of functional circuitry. Journal of Neurobiology 23, 1140-1158.

Crossland, W.J. \& Hughes, C.P. (1978). Observations on the afferent and efferent connections of the avian isthmo-optic nucleus. Brain Research 145, 239-256.

EHRLICH, D. (1981). Regional specialization of the chick retina as revealed by the size and density of neurons in the ganglion cell layer. Journal of Comparative Neurology 195, 643-657.

Ehrlich, D., Keyser, K.T. \& KarTEN, H.J. (1987). Distribution of substance P-like immunoreactive retinal ganglion cells and their pattern of termination in the optic tectum of chick (Gallus gallus). Journal of Comparative Neurology 266, 220-233.

Feyerabend, B., Malz, C.R. \& Meyer, D.L. (1994). Birds that feedon-the-wing have few isthmo-optic neurons. Neuroscience Letters 182, 66-68.

Fritzsch, B., Crapon de Caprona, M.D. \& Clarke, P.G.H. (1990). Development of two morphological types of retinopetal fibers in chick embryos, as shown by the diffusion along axons of a carbocyanine dye in the fixed retina. Journal of Comparative Neurology 300, 405-421.

Galifret, Y. (1968). Les diverses aires fonctionnelles de la rétine du Pigeon. Zeitschrift für Zellforschung 86, 535-545.

Galifret, Y., Conde-Courtine, F., Repérant, J. \& Servière, J. (1971). Centrifugal control in the visual system of the pigeon. Vision Research (Suppl.) 3, 185-200.

Gyger, M., Karakashian, S.J. \& Marler, P. (1985). Avian alarm calling: Is there an audience effect? Animal Behavior 34, 1570-1572.

Gyger, M., Karakashian, S.J., Dufty, A.M., JR. \& Marler, P. (1988). Alarm signals in birds: The role of testosterone. Hormones and Behavior 22, 305-314.

HAhMANN, U. \& GÜNTÜRKÜN, O. (1992). Visual-discrimination deficits after lesions of the centrifugal visual system in pigeons (Columba livia). Visual Neuroscience 9, 225-233.

HaYes, B.P. \& HoldEN, A.L. (1983). The distribution of centrifugal terminals in the pigeon retina. Experimental Brain Research 49, 189-197.

Holden, A.L. \& Powell, T.P. (1972). The functional organization of the isthmo-optic nucleus in the pigeon. Journal of Physiology (London) $223,419-447$.

Holden, A.L. (1977a). Concentric receptive fields of pigeon ganglion cells. Vision Research 17, 545-554.

Holden, A.L. (1977b). Extensive lateral transmission in the inner plexiform layer of the pigeon retina. Vision Research 17, 665-666.

HoLden, A.L. (1990). Centrifugal pathways to the retina: Which way does the "searchlight" point? Visual Neuroscience 4, 493-495.

Maturana, H.R. \& Frenk, S. (1965). Synaptic connections of the centrifugal fibers in the pigeon retina. Science 150, 359-361.

MCGill, J.I., Powell, T.P. \& CowaN, W.M. (1966). The organization of the projection of the centrifugal fibres to the retina in the pigeon. Journal of Anatomy 100, 35-49.

Mcllwain, J.T. (1964). Receptive fields of optic tract axons and lateral geniculate cells. Journal of Neurophysiology 27, 1154-1173.

Meyer, C.C., Parker, D.M. \& Salzen, E.A. (1976). Androgen- 
sensitive midbrain sites and visual attention in chicks. Nature 259 689-690.

Miceli, D., Repérant, J., Rio, J.-P. \& Medina, M. (1995). GABA immunoreactivity in the nucleus isthmo-opticus of the centrifugal visual system in the pigeon: A light and electron microscopic study. Visual Neuroscience 12, 425-441.

MiLes, F.A. (1972a). Centrifugal control of the avian retina. 3. Effects of electrical stimulation of the isthmo-optic tract on the receptive field properties of retinal ganglion cells. Brain Research 48, 115-129.

MILES, F.A. $(1972 b)$. Centrifugal control of the avian retina. IV. Effects of reversible cold block of the isthmo-optic tract on the receptive field properties of cells in the retina and isthmo-optic nucleus. Brain Research 48, 131-145.

Miles, F.A. (1972c). Centrifugal control of the avian retina. II. Receptive field properties of cells in the isthmo-optic nucleus. Brain Research 48, 93-113.

Nickla, D.L., GotTlieb, M.D., Marin, G., Rojas, X., Britto, L.R.G. \& Walliman, J. (1994). The retinal targets of centrifugal neurons and the retinal neurons projecting to the accessory optic system. Visual Neuroscience 11, 401-409.

Pearlman, A.L. \& Hughes, C.P. (1976). Functional role of efferents to the avian retina. II. Effects of reversible cooling of the isthmooptic nucleus. Journal of Comparative Neurology 166, 123-131.

Ramon Y Cajal, S. (1893). La rétine des vertébrés. La Cellule 9, 17-257.

Repérant, J., Micell, D., Vesselkin, N.P. \& Molotchnikoff, S. (1989). The centrifugal visual system of vertebrates: A century-old search reviewed. International Review of Cytology 118, 115-171.

Rochon-Duvigneaud, A. (1943). Les yeux et la vision des vertébrés. Paris: Masson.

Rogers, L.J. \& Miles, F.A. (1972). Centrifugal control of the avian retina. V. Effects of lesions of the isthmo-optic nucleus on visual behaviour. Brain Research 48, 147-156.

Rogers, L.J. \& ANDREw, R.J. (1989). Frontal and lateral visual field use by chicks after treatment with testosterone. Animal Behavior $38,394-405$.
Schmid, H. (1995). Hirondelles et Martinets. Rapport de la Station ornithologique suisse de Sempach 1-37.

SHORTESS, G.K. \& KLOSE, E.F. (1977). Effects of lesions involving efferent fibers to the retina in pigeons. Physiology and Behavior 18, 409-414.

Uchiyama, H. \& Watanabe, M. (1985). Tectal neurons projecting to the isthmo-optic nucleus in the Japanese quail. Neuroscience Letters 58, 381-385.

Uchiyama, H., Matsutani, S. \& Watanabe, M. (1987). Activation of the isthmo-optic neurons by the visual Wulst stimulation. Brain Research 406, 322-325.

UChiYama, H. (1989). Centrifugal pathways to the retina: Influence of the optic tectum. Visual Neuroscience 3, 183-206.

Uchiyama, H. \& Ito, H. (1993). Target cells for the isthmo-optic fibers in the retina of the Japanese quail. Neuroscience Letters 154, 35-38.

UChIYAMa, H. \& Barlow, R.B. (1994). Centrifugal inputs enhance responses of retinal ganglion cells in the Japanese quail without changing their spatial coding properties. Vision Research 34, 2189-2194.

UchiYama, H., Ito, H. \& Tauchi, M. (1995). Retinal neurones specific for centrifugal modulation of vision. Neuroreport 6, 889-892.

Weidner, C., Repérant, J., Desroches, A.M., Miceli, D. \& VesSELKIN, N.P. (1987). Nuclear origin of the centrifugal visual pathway in birds of prey. Brain Research 436, 153-160.

Woodson, W., Reiner, A., ANderson, K. \& Karten, H.J. (1991). Distribution, laminar location, and morphology of tectal neurons projecting to the isthmo-optic nucleus and the nucleus isthmi, pars parvocellularis in the pigeon (Columba livia) and chick (Gallus domesticus): A retrograde labelling study. Journal of Comparative Neurology 305, 470-488.

Woodson, W., Shimizu, T., Wild, J.M., Schimke, J., Cox, K. \& Karten, H.J. (1995). Centrifugal projections upon the retina: An anterograde tracing study in the pigeon (Columba livia). Journal of Comparative Neurology 362, 489-509. 